\title{
Democratizing new Product Development through an Industry-Society Entrepreneurial Partnership.
}

\author{
Evangelos Markopoulos $^{1}$, Emma Luisa Gann ${ }^{1}$, Hannu Vanharanta ${ }^{2}$ \\ ${ }^{1}$ HULT International Business School, Hult House East, 35 Commercial Rd, E1 1LD, London, \\ United Kingdom \\ ${ }^{2}$ University of Vaasa, School of Technology and Innovations, Wolffintie 34, 65200 Vaasa, \\ Finland \\ evangelos.markopoulos@faculty.hult.edu,emma.gann@hotmail.de,hannu@vanharanta.fi
}

\begin{abstract}
New products derive from the industry and the society as well. They can be created in the mind of anyone who sees a need that people can buy, as an outcome of knowledge creation and sharing. This paper presents the structure, concepts, methods and operations of a proposed framework that addresses a new approach on product knowledge registration, evolution and utilization. It explains the co-evolution of a democratic industry-society relationship between the large or small organizations and individuals and provides the process model to apply it in practice. The proposed framework adapts and uses the Company Democracy Model as the base for the development of a practical approach through the evolution of the new product development process over its six escalated stages. Starting from the first level of the idea creation within a knowledge sharing culture, until sixth level of the models which deals with globalization and internationalization strategies.
\end{abstract}

Keywords: New Product Development - Innovation - Society · Consumer · Company Democracy $\cdot$ Shared Value $\cdot$ Entrepreneurship · Management $\cdot$ Leadership

\section{Introduction}

New Product Development (NPD) is a significant concept that drives innovation and growth with direct impact on the society, the markets, and the economy. There are no limits on the size or type of organizations that develop new products. It seems that NDP is a privilege of the organizations who actively invest in $R \& D$ for new products and/or services. However, start-ups tend to drive this concept as their existence depends heavily on insights, ideas, innovations, and uniqueness their products shall have. Thus, large corporations are challenged from the pressure to continuously come up with new products to sustain their market shares, while start-ups are challenge from capital needs to fund their creativity, transform it into new products and place them in the markets.

This dual challenge on NPD can be approached with strategic collaborations, partnerships, mergers, and acquisitions between large-scale organizations and start-ups, but these cannot be considered the most productive, profitable, efficient and effective approaches. 
The new product requirements that can make an impact and succeed in both the industry and society arise primarily from the consumers themselves. Market analysis, consumer preferences and behaviors, surveys, promotion events and other date marketing activities do not always assure the desired outcome on the data, information, and knowledge needed to come up with new products. However, understanding customers' added value needs and creating new rewarding channels of communication and cooperation can ignite profound circles of collaborative innovation activities.

The creation of a generic framework to provide a democratic innovation culture and operations through which individuals will be able to promote their new product ideas to the industry could be a potential solution in the found problem. In this new suggested approach data, information, knowledge, desires, needs, and wishes could be recorded in an independent organization, that can link the companies search for new product ideas directly with the consumers. Such a framework can benefit large organizations to reduce $\mathrm{R} \& \mathrm{D}$ costs, avoid mergers and acquisitions, and commit to long term investments by providing entrepreneurial opportunities to individuals who desire to share their ideas in practice. Furthermore, financial and entrepreneurial incentives can be provided to individuals in order to cooperate and co-develop, to the extent of their contribution, new useful and innovative products. This win-win relationship can be executed through a democratic approach, which provides equal opportunity for anyone to turn any idea into an actual product.

\section{NPD in Management Science}

NPD sustains long term organizational growth, increases profits and financial stability due to the continuous presence of the organization in the market. The need to remain visible and present in the eyes of the consumers is what primarily drives NPD. This continuous relationship with the customers, sustains and increases the market share. NPD can be mostly considered as a management strategy rather than a product management process. It incorporates product improvements, adaptations, extensions, and innovation on new or existing products, while at the same time incorporates the marketing, the communication, the finance and the entrepreneurial discipline as well, in a well-balanced effort to maintain organizational market lead and impact.

Today more than $25 \%$ of the industry total profits are generated through new product launches [1]. New products contribute on increasing brand loyalty of existing customers via its evolution and alignment on the market needs and trends, but also on the creation of completely new markets. Furthermore, NPD can operate as a risk diversification strategy through which selective products test the market needs and experiment with ideas that can change the route of a product or an industry. Fast changing market demands require agility on the creation or evolution of the products [2]. This agility reduces the risk of products being outdated with controlled evolution in minor or major features, or even with the use of effective communication strategies when the change is not on the product itself, but on its packaging, appearance or content volume [3].

Based on the organizational strategy, NPD can be used on a global scale, to drive socio-economic and environmental change, technological advancements and improve efficiency by responding to prevailing challenges [4]. New products can, and have, 
been designed to support new ideas, concepts, lifestyles and needs that reflect to the fast evolving environmental, political, social and cultural changes.

Even that NPD is not necessarily related with innovation, it is that the most innovative organizations can lead NPD in either originality on their products or meaningful innovative variations on them. Bloomberg gives the global innovation lead to Korea with a score of 87.3 , followed by Germany with 87.3 and Finland 85.5 [5]. Figure 1 indicates that innovation is not quite related to the country size or its position in the global economy. Innovative countries do not necessarily derive from the leading economies but they can be considered the ones with the most global impact from the innovations they generate regardless when and by whom these innovations will be applied into new products or services. It is the quality of innovation and not the quality. Qualitative innovations can generate multiple products or applications. Canada for example is $8^{\text {th }}$ on patents activity but $20^{\text {th }}$ in the innovation index, while S. Korea is $1^{\text {st }}$ on innovation and $20^{\text {th }}$ on patents.

\begin{tabular}{|c|c|c|c|c|c|c|c|c|c|c|c|}
\hline $\begin{array}{l}2019 \\
\text { Rank }\end{array}$ & $\begin{array}{l}2018 \\
\text { Rank }\end{array}$ & $\begin{array}{c}\text { YoY } \\
\text { Change }\end{array}$ & Economy & $\begin{array}{l}\text { Total } \\
\text { Score }\end{array}$ & $\begin{array}{c}\text { R\&D } \\
\text { Intensity }\end{array}$ & $\begin{array}{l}\text { Manufacturing } \\
\text { Value-added }\end{array}$ & Productivity & $\begin{array}{l}\text { High-tech } \\
\text { Density }\end{array}$ & $\begin{array}{c}\text { Tertiary } \\
\text { Efficiency }\end{array}$ & $\begin{array}{l}\text { Researcher } \\
\text { Concentration }\end{array}$ & $\begin{array}{r}\text { Patent } \\
\text { Activity }\end{array}$ \\
\hline 1 & 1 & 0 & S. Korea & 87.38 & 2 & 2 & 18 & 4 & 7 & 7 & 20 \\
\hline 2 & 4 & +2 & Gemany & 87.30 & 7 & 3 & 24 & 3 & 14 & 11 & 7 \\
\hline 3 & 7 & +4 & Finland & 85.57 & 9 & 16 & 5 & 13 & 9 & 8 & 5 \\
\hline 4 & 5 & +1 & Switzerland & 85.49 & 3 & 4 & 7 & 8 & 13 & 3 & 27 \\
\hline 5 & 10 & +5 & Israel & 84.78 & 1 & 33 & 8 & 5 & 36 & 2 & 4 \\
\hline 6 & 3 & 3 & Singapore & 84.49 & 13 & 5 & 11 & 17 & 1 & 13 & 14 \\
\hline 7 & 2 & -5 & Sweden & 84.15 & 4 & 15 & 9 & 6 & 20 & 5 & 25 \\
\hline 8 & 11 & +3 & U.S. & 83.21 & 10 & 25 & 6 & 1 & 43 & 28 & 1 \\
\hline 9 & 6 & -3 & Japan & 81.96 & 5 & 7 & 22 & 10 & 39 & 18 & 10 \\
\hline 10 & 9 & -1 & France & 81.67 & 12 & 41 & 13 & 2 & 11 & 20 & 15 \\
\hline 11 & 8 & -3 & Denmark & 81.66 & 8 & 21 & 15 & 12 & 19 & 1 & 28 \\
\hline 12 & 12 & 0 & Austria & 80.98 & 6 & 11 & 12 & 24 & 8 & 9 & 18 \\
\hline 13 & 14 & +1 & Belgium & 80.43 & 11 & 26 & 10 & 9 & 41 & 16 & 9 \\
\hline 14 & 13 & -1 & Ireland & 80.08 & 32 & 1 & 1 & 16 & 15 & 14 & 38 \\
\hline 15 & 16 & +1 & Netherlands & 79.54 & 16 & 29 & 21 & 7 & 42 & 12 & 12 \\
\hline 16 & 19 & +3 & China & 78.35 & 14 & 13 & 47 & 11 & 6 & 39 & 2 \\
\hline 17 & 15 & -2 & Norway & 77.79 & 17 & 49 & 23 & 15 & 17 & 10 & 11 \\
\hline 18 & 17 & -1 & U.K. & 75.87 & 20 & 45 & 26 & 14 & 5 & 21 & 19 \\
\hline 19 & 18 & -1 & Australia & 75.38 & 19 & 56 & 17 & 20 & 18 & 15 & 6 \\
\hline 20 & 22 & +2 & Canada & 73.65 & 22 & 39 & 27 & 22 & 31 & 19 & 8 \\
\hline 21 & 20 & -1 & Italy & 72.85 & 24 & 22 & 20 & 19 & 29 & 29 & 26 \\
\hline 22 & 21 & -1 & Poland & 69.10 & 36 & 20 & 40 & 18 & 16 & 38 & 37 \\
\hline
\end{tabular}

Fig. 1. Bloomberg 2019 innovation index.

\section{Major NPD Challenges}

Maintaining a successful flow on new products is a very challenging goal that can lead to great financial and reputation disasters if not performed effectively. The effort on inventing new product features or communication practices is highly expensive and risky due to the diversity of the customers that cannot be captured through ordinary data collections activities. Major challenges on NDP can be categorized into lack of human intellectual capital, lack of innovation, and lack of collaborative thinking.

Specifically, human intellectual capital challenges can be considered the organizational struggle on finding human resources that have the knowledge as well as the skills to contribute in the development of new products that fulfil the organization's objectives and simultaneously be relevant to the market.

Furthermore, the lack of innovation is a challenge faced primarily by mature organizations that have difficulties to change the winning recipe that drive their operations around a successful business model based on existing products or services [6]. Such 
organizations learned to expect certain profit from their operations, therefore new products development that might cause disturbance to their cashflow and planning, is systematically avoided.

Lastly, lack of innovation has been attempted to be tackled with strategic collaboration initiatives, but this brings up the challenge of collaborative thinking which requires both parties to be aligned on the same point of view, mentality, goals and visions for such partnerships to work successfully. Collaborative thinking is a multi-dimensional challenge as it is related to the organizational needs on exchanging knowledge and combining practices towards generating new products under the company itself or through joint product lines. Successful products that derive from collaborative thinking have been found primarily in the design industries with collaborations between various organizations such as Adidas, Porsche, Goodyear, H\&M, Karl Lagerfeld and others. In these cases, new products were developed by merging only ideas and not organizational entities of any type. On the other hand, new products have also been developed after significant corporate mergers and acquisitions mostly on high tech or high-cost product development industries such as the telecommunications (Sony-Ericsson, Fujitsu-Siemens), the automobile industry (Mercedes-Benz), or other critical industries (ShellRoyal Dutch Petroleum) [7]. NPD approaches through collaborative products can be highly expensive on either profits distribution or merging investments. The return on investments has to be quite significant for such cases but this does not always seem to work. Failures, such as the Daimler -Chrysler or the America On Line (AOL)-Time Warner merger, indicate that collaborative NPD can be of high cost and risk [8].

\section{Democratizing the NDP Process}

The NPD barriers can possibly be avoided if a close relationship of the industry with the society can be achieved, since most NDP challenges are innovation and collaboration oriented. As of today, practices such as questionnaires, surveys, focus groups, and product sample distribution, among others are employed by the majority of the organizations globally. Even that there is no specific research indicating the effectiveness of these practices in NPD, it can be considered that they mostly contribute to the dissemination and evolution of existing products instead of creating new ones.

There is tremendous cost on original knowledge generation with direct impact on the society, as this requires well-structured communications units, $R \& D$ product units, corporate innovation culture and strategic partnerships.

What organizations seem to neglect in this effort is the society itself as a source of ideas and knowledge generation engine for NPD. The society is the people and the people have needs that can use used to inspire NPD. The elicitation of these needs can be turned into valuable knowledge that can be transformed into new products. However the challenge in this case in the incentivized engagement of the people to provide valid, true and valuable knowledge instead of information.

This challenge can be addressed with the democratization of the NPD process through an integrated framework that can link any person with any idea to any organization seeking to use such an idea for new and valuable products. This framework needs to be based on a number of incentives for both parties. 
The initial reward for those who have such ideas is that they can benefit and improve their lives with the new products and services that will derive from their implementation. In addition, citizen must be assured that their knowledge is registered under their name and therefore any type of utilization from any organization will return the related benefits according to their involvement. This concept empowers people to actively create conceptual solutions for the daily life problems. Organizations can support this engagement by providing the relevant resources and infrastructure to the ones having the ideas in order to develop their desired products.

\section{The Democratic New Product Development Model (DeNPD)}

The democratization of the New Product Development process can be achieved through the Company Democracy Model as the base framework for the adaptation of a society-industry democratic and co-evolutionary relationship.

The Company Democracy Model (CDM) [9], [10], is an evolutionary process framework based on the ancient Hellenic wisdom through which the interpretation Delphic maxims such as 'Know Thyself', 'Metron Ariston'and 'Miden Agan' [11] are applied in a business context. The model is executed in a spiral formation and is aligned with the Evolute methodology for the generation of knowledge and its transformation into innovation [12]. Using ontologies and taxonomies the knowledge is classified and evolved based on the capacity, capability, competence, and maturity of the human resources [13], turning organizational tacit knowledge into explicit [14]. The adaptation of the CDM into a Democratic New Product Development framework follows the six levels pyramid structure in which the organization and the knowledge contributor coevolve in the transformation on an idea into a global innovative new product (Fig. 2).

At level 1, the model creates the democratic culture and the process framework needed for ideas for new products to be generated, recorded and shared. It is the most critical stage of the model where the participation of the society impacts its overall execution and success. Level 2 is based on the utilization of the human capital with the identification of the best knowledge contributors and the invitation to them to join a team with corporate experts in order to develop their ideas furthermore. In this stage, the idea holder has the option to participate actively by taking the lead in the maturity of the idea and the design of the new product or stay less active by following the process by providing feedback. Once the idea of the new product has been designed and approved the level 3 takes place where the actual new product is being initially developed as a prototype and then as a fully developed product, ready to be launched in the market. This is the product engineering level and the level that in most cases closes the new product development cycle unless the product behaves exceptionally well in the market, indicates innovative characteristics, and wide consumer acceptance.

In this case, process moves to level 4 where the innovative characteristics as supported furthermore making the product robust and solid on what leads its innovative impact on the market and the industry. With a highly innovative product, the process enters level 5 where the unique competitive elements of the product are emphasized in the communication, marketing and dissemination strategies impacting the global marketing strategy, sales, and operations. The execution of a competitive based strategy leads to level 6 where the product makes an impact on the organization itself due to its 
success and becomes part of the organizational structure as a new product line, business unit, spin-off, part of a strategic alliance via mergers and acquisitions or through other forms of international and global success utilization.

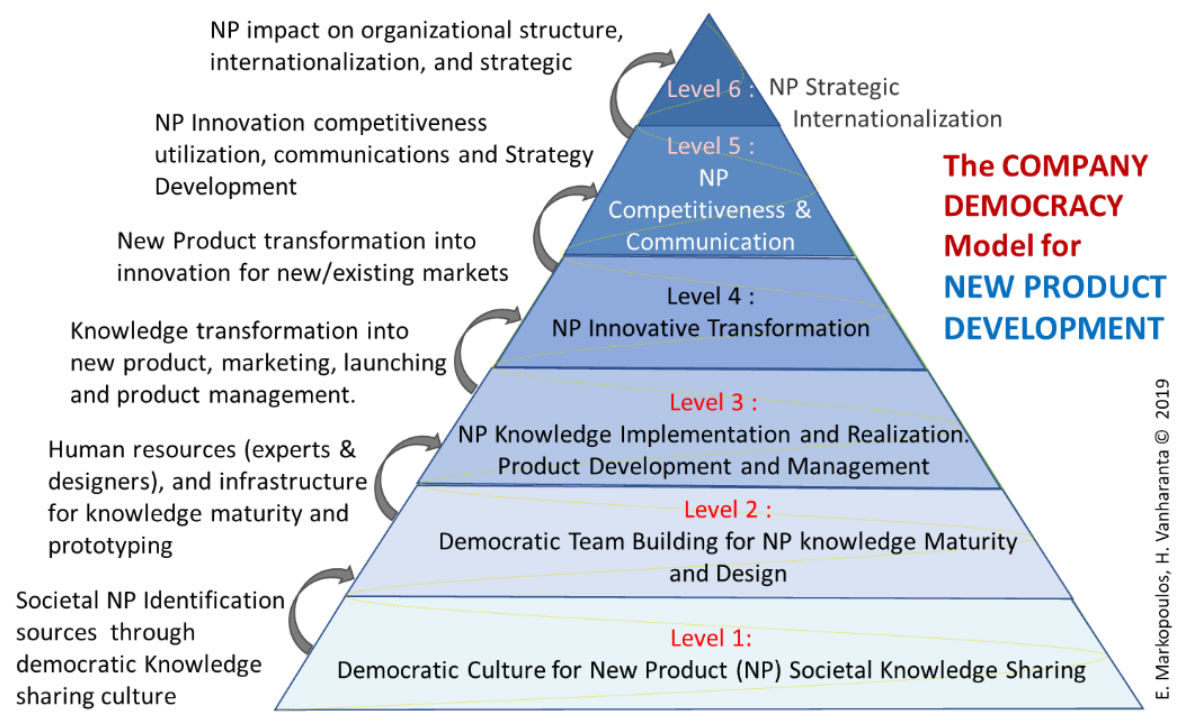

Fig. 2. The Democratic New Product Development Model (DeNPD)

The evolution of an idea from the citizen up to the creation of a world-class innovative product is achieved over a period of time that is defined by the idea's potential. In this journey, the relationship of the citizen with the company can also go through a number of progressive stages related to the success of the product. The relationship of the product success and the commitment of the citizen are aligned with the benefits the citizen receives from this process. The evolution of the benefits offered to a participating citizen in the DeNPD can be represented by an inverse pyramid where the benefits are limited in the start but increase over the success of the product (shown in Fig. 3).

In this inverse, benefits, pyramid, level one provides the minimum benefits as the idea is submitted in draft format, the documentation is limited, and the effort is restricted to the completion of such documentation. Compensation can be granted in the case once an organization requests further documentation. In this sense, the commitment of the citizen is limited as well. The work submitted is registered under the citizen which is an alternative form of intellectual, instead of monetary, compensation.

At level two the new product idea has been selected by and organization and the citizen is required to participate in the evolution of the idea to a mature product design. In this case, the commitment of the citizen, if the offer is accepted, increases with the participation in the design team receiving the compensation for the work executed. However, the citizen can withdraw from the process. In this case the company continues with their own resources.

At level three the citizen takes the role of the project manager, based on the commitment and contribution placed in level two. The compensation can be relevant to the 
time and effort placed in the development of the idea into the actual product. Until this point, no profit shares are provided to the citizen as the success of the new product in uncertain. Level four is activated once the product achieves significant success and can justify its transformation effort into an innovative product. In this case the citizen receives part of the intellectual property shares and also the option to be part of the innovation transformation process.

Level five increases the organization's commitment on the product, but also participation of the citizen in the strategic management and communication on the utilization of the new innovative product. Being part of the journey from the product's initial idea until its global utilization, the citizen can receive an executive role on the management of the product. Level six is after the product international success where citizen can receive partnership on the organizational schema formed to support the product.

\section{The COMPANY DEMOCRACY Model for NEW PRODUCT DEVELOPMENT} COMMITMENT VS BENEFITS VS SUCCESS CASES

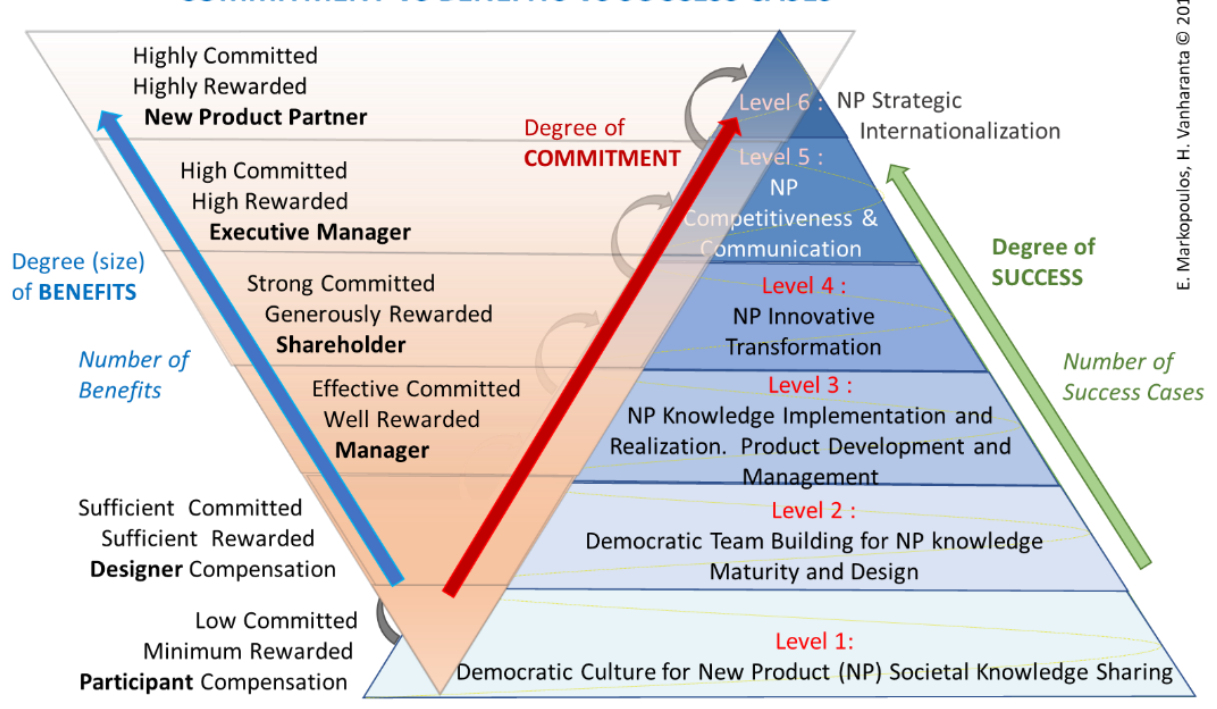

Fig. 3. Degree of commitment, success and benefits in the DeNPD

The model indicates that existing opportunities for personal growth and development can be exponential from level to level, but only a few ideas become world-class innovative products. The inverse pyramid presents this concept clearly. At the higher levels (4-6) the benefits are many as few are the successful ideas, while at the lower levels (1$3)$ the benefits are limited as the ideas are in draft stage and their success is uncertain.

\section{Implementation Forms of the DeNPD Framework}

The success of the DeNPD relies heavily on a society-industry relationship that must be driven by credibility and security to the citizen in order to provide the confidence and trust needed to participate. Such a goal can be achieved with the establishment of 
a regional or national independent organization which could either be state governed or privately governed (chamber of commerce or local, regional, national, industry federation). The organization shall act as a New Product House, similar to the operations of the companies houses with the difference that the registered information will be related to the work submitted on new product development ideas, concepts, designs, prototypes and other variations of work on products that have not been commercially launched yet.

This New Product House (NPH) house shall act responsibly for the credibility of the overall process. The purpose of this organization is to ensure the matching of the right new product idea with the right organization request. The NPH operates at the first level of the DeNPD, setting up a democratic culture, environment and infrastructures for all those who wish to contribute. It must be noted that the knowledge, idea or work contributors do not always seek entrepreneurial or corporate careers, but mostly expect to see in the market a product or service they feel a need to have. Figure 4 presents a highlevel process of this democratization concept on the New Product Development, with the NPH to orchestrate this industry society relationship.

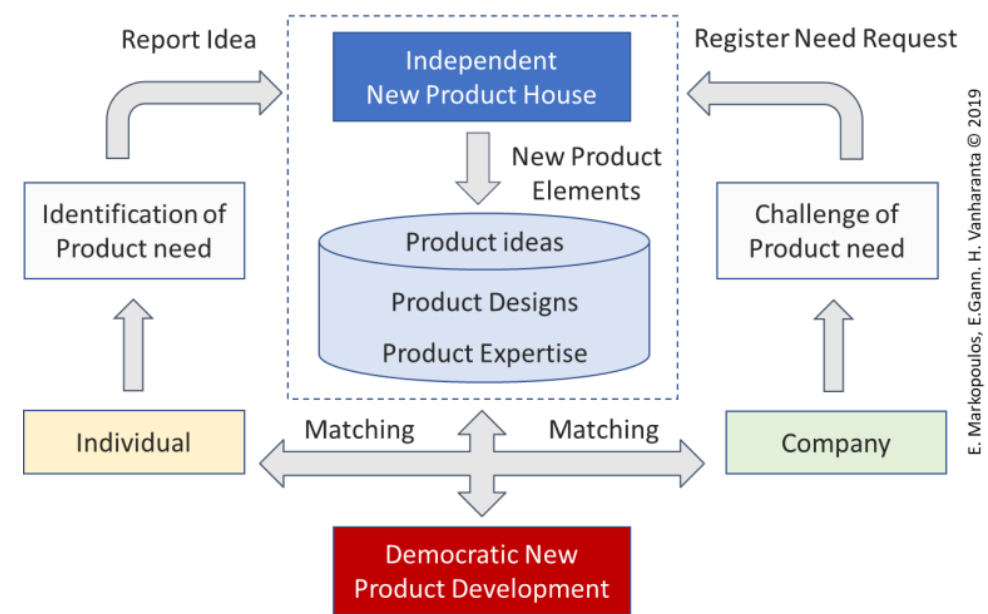

Fig. 4. The New Product House Operations.

Access to the NPH can be granted to both the citizens and the organizations. Companies can request feedback on new product needs or access ideas, designs or even prototypes. These requests can be visible to all, and the collaboration between the industry and the society can be established through the NeNDP framework. This winwin relationship provides the opportunity to all citizens to share their new product ideas, and to participate in corporate projects initiatives and activities on new products development. It also provides access to all organizations to search or request such knowledge by returning the relevant rewards, incentives and opportunities to utilize it.

The Democratic New Product Development concept combines the three main stakeholders (Society, New Product House, and Industry) and creates a knowledge-sharing environment between the society and the industry under the coordination, security and knowledge safeguarding of an independent institution formed to support this goal through the democratization of new product development challenge. 


\section{$7 \quad$ Industry-society partnership. Social and Shared Value innovation}

The DeNPD framework extends its scope into a more social dimension by empowering individuals to contribute to the economy to the, society but also to their personal development and growth. The framework is aligned with the shared value innovation and development principles in a purely democratic way which assures credibility, recognition and rewards to all who wish and can contribute.

Share value innovation describes the process that aims mutual gains for the industry and the society, with organizations to generate economic returns by addressing social issues and adding value to the society [15].

The social product development model today extends the open innovation and moves beyond the traditional customer-involvement models towards the social engagement of individuals [16], [17]. Under democratic procedures the people, as fully involved actors in the development of new products, participate is all stages, from the ideas generation to the actual product realization.

The framework inspires both the people and the organizations to collaborate in a coevolutionally relationship forming a society industry partnership. This ethical dimension creates the added value on this approach and redefines the contribution of the companies to the society not only as product providers and therefore profit makers, but also as opportunity providers and therefore profit givers. The profit-making-giving circular approach is what democratic social shared value new product development is all about.

This re-definition of the shared value innovation under the democratic concept and towards new product development can impact tremendously the way new products are conceived, developed and even used. The world strives for the application and adaptation of the democratic values that extend the freedom of speech to the freedom of act. All who can and wish to contribute towards making this world better need and must have the opportunity of a fair share on this effort.

\section{Conclusions}

The Democratic New Product Development model is a Y-theory liberal thinking model, based on the values and opportunities democracy offers to all. It provides the channel for the society to interact with the industry for shared value in new or existing products and services. The model is based on the Company Democracy Model for innovation and has been altered to match the new product development challenge through a co-evolutionary human and product development process. The effectiveness of the model relies on the effectiveness of the NPH, the intermediate organization needed to coordinate knowledge elicitation and industry requests or needs. The organization sets the standards and monitors the new product development process. It also validates and verifies the knowledge and the overall execution process needed to create the security and credibility that will attract the participation and commitment of the society. The DeNPD is at a theoretical stage and further research will be conducted to identify the legal, social, technical, cultural and financial elements for the process optimization that will lead it to a pilot adaptation in the industry. 


\section{References}

1. McKinsey. https://www.mckinsey.com/business-functions/marketing-and-sales/our-insights/how-to-make-sure-your-next-product-or-service-launch-drives-growth

2. Leite M., Braz V.: Agile manufacturing practices for new product development: industrial case studies, Journal of Manufacturing Technology Management, Vol. 27 Issue: 4, pp.560--576 (2016)

3. Lee, Y., O'Connor, G. C.: The Impact of Communication Strategy on Launching New Products: The Moderating Role of Product Innovativeness. Journal of Product Innovation Management, vol 20, pp 4--21 (2003)

4. Global Entrepreneurship Index. https://thegedi.org/wp-content/uploads/dlm_uploads/2017/11/GEI-2018-1.pdf

5. Bloomberg. https://www.bloomberg.com/news/articles/2019-01-22/germany-nearlycatches-korea-as-innovation-champ-u-s-rebounds

6. Forbes. https://www.forbes.com/sites/tendayiviki/2018/11/04/why-large-companiescontinue-to-struggle-with-innovation/\#47a503bc67b4

7. Daimler. https://www.daimler.com/company/tradition/mercedes-benz/history.html

8. Köhler HD.: From the Marriage in Heaven to the Divorce on Earth: the DaimlerChrysler Trajectory since the Merger. In: Freyssenet M. (eds) The Second Automobile Revolution. Palgrave Macmillan, London (2009)

9. Markopoulos E., Vanharanta H.: Democratic Culture Paradigm for Organizational Management and Leadership Strategies - The Company Democracy Model. Proceedings of the 5th International Conference on Applied Human Factors and Ergonomics AHFE 2014 (2014).

10. Vanharanta H., Markopoulos E.: Creating a Dynamic Democratic Company Culture for Leadership, Innovation, and Competitiveness. 3rd Hellenic-Russian Forum. Sept.17. (2013).

11. Parke H., Wormell D.: The Delphic Oracle, Basil Blackwell, vol. 1, pp 389 (1956).

12. Kantola, J., Vanharanta, H., Karwowski, W.: The Evolute System: A Co-Evolutionary Human Resource Development Methodology. In the International Encyclopedia of Ergonomics and Human Factors. Karwowski, W., CRC Press. (2006).

13. Paajanen, P., Piirto, A., Kantola, J., Vanharanta, H.: FOLIUM - Ontology for Organizational Knowledge Creation. 10th World multi-conference on systemics, cybernetics, and informatics. (2006).

14. Nonaka I., Takeuchi H., The Knowledge-Creating Company: How Japanese Companies Create the Dynamics of Innovation, New York, Oxford University Press (1995).

15. Markopoulos E., Vanharanta. H.: The Company Democracy Model for the Development of Intellectual Human Capitalism for Shared Value, Procedia Manufacturing, vol 3, pp 603--610 (2015)

16. Forbes H., Schaefer D.: Social Product Development: The Democratization of Design, Manufacture and Innovation, Procedia CIRP, vol 60, pp 404-409 (2017)

17. K. Abhari, E.J. Davidson, B. XiaoMeasure the Perceived Functional Affordance of Collaborative Innovation Networks in Social Product Development. 49th Hawaii International Conference on System Sciences. pp 929--938 (2016) 